This paper is published as part of a Dalton Transactions themed issue entitled:

\title{
New Talent: Americas
}

Guest Editors: John Arnold, Dan Mindiola, Theo Agapie, Jennifer Love and Mircea Dincă

Published in issue 26, 2012 of Dalton Transactions

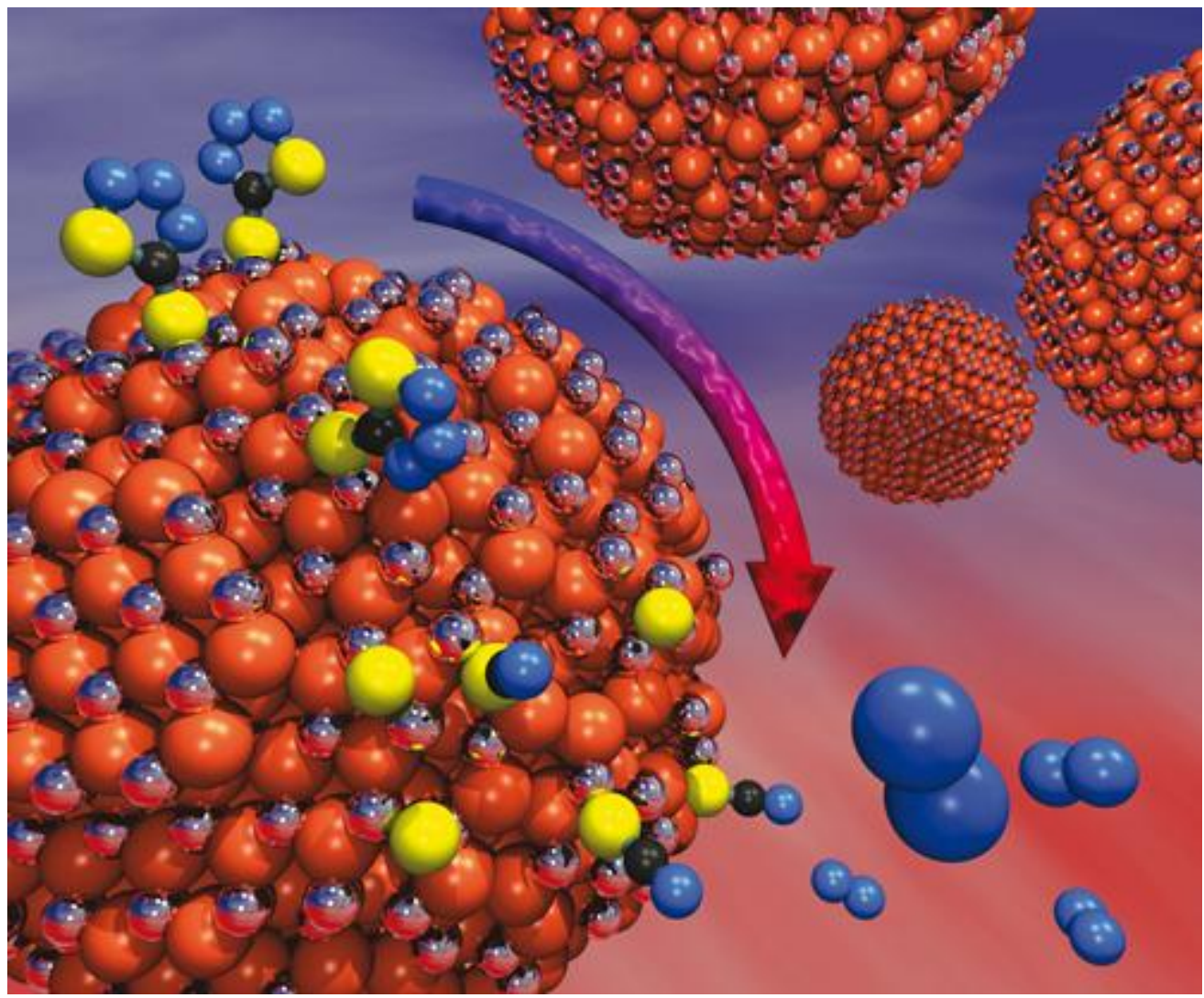

Image reproduced with permission of Richard L. Brutchey

Articles published in this issue include:

Synthesis and reactivity of 2-azametallacyclobutanes

Alexander Dauth and Jennifer A. Love

Dalton Trans., 2012, DOI: 10.1039/C2DT30639E

Perceiving molecular themes in the structures and bonding of intermetallic phases:

the role of Hückel theory in an ab initio era

Timothy E. Stacey and Daniel C. Fredrickson

Dalton Trans., 2012, DOI: 10.1039/C2DT30298E

Cycloruthenated sensitizers: improving the dye-sensitized solar cell with classical inorganic chemistry principles

Kiyoshi C. D. Robson, Paolo G. Bomben and Curtis P. Berlinguette

Dalton Trans., 2012, DOI: 10.1039/C2DT30825H

Visit the Dalton Transactions website for more cutting-edge inorganic chemistry www.rsc.org/dalton 


\title{
New talent: Americas
}

\author{
DOI: $10.1039 / c 2 d t 90087 d$
}

\section{Daniel J. Mindiola, ${ }^{* a}$ John Arnold, ${ }^{b}$ Theo Agapie, ${ }^{c}$ Jennifer Love ${ }^{d}$ and Mircea Dinca ${ }^{e}$}

I once read the following passage: humankind did not run out of stones to move from the stone age (Paleolithic) to the more evolved bronze stage (Neolithic). It is thought that this change was the result of the development of agriculture due to the climate changing to warmer weather. We can also make the same analogy in science: we do not need to run out of coal, crude oil, natural gas or other natural resources to begin thinking about the next era of humanity. Science is constantly evolving, being parallel to technology and world change (climate, politics and economic changes, among other important factors). As a result, if we fail to evolve as scientists, we become part of a "new" stone age. Therefore, new insights and ideas are part of the foundation to change and to make possible the evolution of a subject. Chemistry, as we all now know, is a remarkably broad subject intersecting the fields of physics and mathematics, biology, geology and medicine. More specifically, chemistry is a topic that can no longer be labeled as the science that studies the nature of matter and its transformations. Chemistry impacts far beyond into physics, mathematics, biology and biochemistry and, in the last century, industry. Chemistry is at the forefront of science but only change, coupled with curiosity, is what will make this area a fascinating journey.

Multifaceted chemistry is what brands this subject complex and challenging, but this same origin of complexity is what has enabled this physical science to evolve over the ages. Why am I emphasizing the broader implications of chemistry? Because inorganic chemistry can no longer be labeled as a specialized field that focuses only on metallic and metal ions, it goes far beyond this.

In this special "New talent: Americas" issue in Dalton Transactions, we showcase a group of young, talented scientists who combine multiple subdisciplines of chemistry to solve difficult and challen- ging problems, but also to address the fundamental inquiries which relate to the intrinsic aspects of new molecules with unusual properties, storage materials, catalysts, biofunctional systems and sensors.

We hope the readership of Dalton Transactions appreciates the energy embedded in the manuscripts compiled in this special issue. Contributors were chosen based on a broad range of topics involving bioinorganic, catalysis, materials, organometallic and theoretical chemistry and/or combinations thereof. The guest editors and I are also proud to announce that this issue contains over 50 contributions from the Americas, most of which entail research communications and articles, in addition to some short reviews.

We hope you enjoy this selection of papers that features some of the brightest young inorganic chemists on the American continent. So take a seat, relax with a cup of joe or tea and let your mind go free while reading some of the contents in this issue.

\footnotetext{
${ }^{a}$ Department of Chemistry, Indiana University, Bloomington, Indiana, 47405, USA

${ }^{b}$ Department of Chemistry, University of California, UC Berkeley, Berkeley, California, 94720, USA

${ }^{c}$ Chemistry, California Institute of Technology, 1200 California Boulevard, Pasadena, California, 91125, USA

${ }^{d}$ Chemistry Department, University of British Colombia, 2036 Main Mall, Vancouver, V6T

1Z1, Canada

${ }^{e}$ Chemistry, Massachusetts Institute of

Technology, 77 Massachusetts Avenue,

Cambridge, Massachusetts, 02139, USA
} 